\title{
Alleviation of Drought Stress in White Clover after Inoculation with Arbuscular Mycorrhizal Fungi
}

\author{
Xiao-Qing TUO ${ }^{1,2}$, $\mathrm{Li} \mathrm{HE}^{1}$, Ying-Ning ZOU ${ }^{1,2 *}$ \\ ${ }^{1}$ Yangtze University, College of Horticulture and Gardening, Jingzhou, Hubei 434025, \\ China;m13872230291@163.com;714048641@qq.com; zouyingning@163.com (*corresponding author) \\ ${ }^{2}$ Yangtze University, Institute of Root Biology, Jingzhou, Hubei 434025, China
}

\begin{abstract}
White clover is extremely susceptive to drought stress (DS), while it is not clear whether arbuscular mycorrhizal fungi (AMF) enhance drought tolerance of the plant. This study was carried out to evaluate effects of two AMF species, Funneliformis mosseae and Paraglomus occultum, on flavonoid, soluble protein, proline, and nutrient uptake in roots of white clover under well-watered (WW) and DS conditions. Root colonization by $F$. mosseae and $P$. occultum was heavily decreased by 7-week DS treatment. Mycorrhizal plants showed considerably greater biomass production in shoot, root, and total (shoot+root) than non-mycorrhizal plants, irrespective of soil water status. AMF inoculation led to significantly higher root soluble protein and proline accumulation under WW and DS and root flavonoid level under DS, regardless of AMF species. Root N, P, K and Cu concentrations were dramatically increased by mycorrhization under WW and DS, and root Ca, Mg, Fe, and Mn levels were significantly higher in AMF plants than in non-AMF plants under WW. It concluded that AMF strongly enhanced plant growth and drought tolerance of white clover by greater nutrient absorption and protective substances (soluble protein, proline, and flavonoid) accumulation.
\end{abstract}

Keywords: antioxidant, legume, mycorrhizal colonization, osmotic adjustment, symbiosis, water stress

\section{Introduction}

Drought stress (DS), one of most predominant abiotic stresses, often results in an evident decrease in crop productivity and growth throughout the world (Zhang et al., 2016). Drought stress causes the damage to net photosynthetic behavior, electron transport system, and oxidative burst (Saraswathi and Paliwal, 2011). In addition, DS has adverse effects on mineral nutrient uptake and osmotic adjustment as the result of dehydration in plants. Therefore, enhancing drought tolerance of plants is essential for plant growth and survival in arid and semi-arid area.

Arbuscular mycorrhizal fungi (AMF) widely distribute among various kinds of soil ecosystems, which can form symbiotic associations with roots of $80 \%$ terrestrial plant species. Mycorrhizal symbiosis can benefit from carbon provided by host plants and make larger contributions to plant growth nutrient and water uptake. Studies in the past had demonstrated that AMF had the potential capacity to enhance drought tolerance of host plants under DS (Kapoor et al., 2004; Lazcano et al., 2014). Underlying mechanisms under mycorrhization attribute to increasing water uptake and transport by external hyphae at low soil moisture level, improving osmotic adjustment by means of accumulating osmoprotectants (sugar, protein, proline, etc.), increasing photosynthetic activities, promoting acquisition of mineral nutrients especially $\mathrm{P}$, activating antioxidant protected systems to eliminate the accumulation of reactive oxygen species, and release of glomalin to improve soil structure (Smith et al., 2010; Li et al., 2012; Wu et al., 2014, 2016a, 2016b). Moreover, mycorrhizal effects on drought tolerance of plants depend on AMF species but also host plant species, with greater compatibility.

White clover (Trifolium repens L.) is one of legume herbages with high fed quality, and is always planted separately in different ecological environments as a pure stand or mixed with other grass varieties. White clover is also widely used to ground covers and urban parks due to its high ornamental value, where abiotic and biotic stresses are often suffered. In addition, white clover is heavily sensitive to soil moisture due to shallow root systems, and thus soil DS has become the major factor restricting their growth (Li and Pen, 2012). However, the information about AMF effects on drought tolerance of white clover is limited, and underlying mechanistic insights involved are not understood.

As AMF have shown the capacity to enhance drought tolerance of plants, we hypothesize that AMF could enhance drought tolerance of white clove through several physiological mechanisms. Therefore, the purpose of this study was to 
confirm the above hypothesis by the analysis of growth, soluble protein, proline, flavonoid, and nutrients.

\section{Materials and Methods}

\section{Plant culture}

Seeds of white clover were soaked in $75 \%$ alcohol for $10 \mathrm{~min}$ for surface sterilization, rinsed four times with distilled water, and then sown in plastic pots $(15.5 \mathrm{~cm}$ top diameter $\times 12 \mathrm{~cm}$ bottom diameter $\times 13.5 \mathrm{~cm}$ height $)$ filled with $2.2 \mathrm{~kg}$ autoclaved $\left(121^{\circ} \mathrm{C}\right.$, $0.11 \mathrm{Mpa}, 2 \mathrm{~h})$ substrates of soil and sand $(4: 1, \mathrm{v} / \mathrm{v})$. Fifteen seeds of white clover were sown in a pot and thinned in the density of 12 seedlings/ pot after 15 days. At the time of sowing, 1800 spores of two AMF species viz., Funneliformis mosseae (T.H. Nicolson \& Gerd.) C. Walker \& A. Schüßler or Paraglomus occultum were mixed with the growth substrates. Non-AMF treatment also received an equal amount of autoclaved $\left(121^{\circ} \mathrm{C}\right.$, $0.11 \mathrm{Mpa}, 2 \mathrm{~h})$ inoculums and $2 \mathrm{~mL}$ inoculum filtrate $(25 \mu \mathrm{m}$ filter) to keep similar microbial communities, with the exception of AMF. All the treated pots were placed in a greenhouse from April 1 to July 31, 2015, where the photosynthetic photon flux density is $768 \mu \mathrm{mol} / \mathrm{m}^{2} / \mathrm{s}$, day/night temperature $28 / 20^{\circ} \mathrm{C}$, and relative humidity $80 \%$.

\section{Experimentaldesign}

The pot experiment was conducted as a $2 \times 3$ factorial randomized block design with two water regimes (WW, 75\% of maximum water holding capacity of soils; DS, 55\% of maximum water holding capacity of soils) and three mycorrhizal inoculations ( $F$. mosseae, $P$. occultum and non-AMF). Each treatment was replicated five times, resulting in a total of 30 pots.

The water treatments were implemented 11 weeks after the sowing. The substrate water content was determined daily through weighing the pot and then supplying the lost water to maintain the designed water content of the substrate at the target level. AM and non-AM plants were maintained for seven weeks under WW and DS conditions before plant harvesting.

\section{Variable determinations}

After seven weeks of DS treatment, plants were harvested and shoot and root fresh weight was determined. Part of root samples was stored at $-80^{\circ} \mathrm{C}$ for the biochemical analysis.

Fresh $1-\mathrm{cm}$ root segments were cleared by $10 \%(\mathrm{w} / \mathrm{v}) \mathrm{KOH}$ and stained with $0.05 \%$ trypan blue by the protocol outlined by Phillips and Hayman (1970). The root AM colonization was expressed as the percentage of the infected root length against the observed total root length.

Root flavonoid was determined as per the method of Chen $e t$ al. (2001). Root proline concentration was measured with the acid ninhydrin method described by Bates et al. (1973). A 0.2-g root sample was homogenized in $5 \mathrm{~mL}$ of $0.1 \mathrm{M}$ phosphate buffers ( $\mathrm{pH} 7.8$ ) and centrifuged at $4000 \mathrm{~g}$ for $10 \mathrm{~min}$ at $4{ }^{\circ} \mathrm{C}$. The supernatant was determined for soluble protein concentration using the protocol of Bradford (1976).

Nitrogen $(\mathrm{N})$ concentration was determined using the Kjeldahl method (Sivasankar and Oaks, 1995). Phosphorous (P) was analyzed by a vanadate molybdate method using an UV/visible spectrophotometer following Chapman and Pratt (1962). The content of potassium $(\mathrm{K})$, calcium (Ca), magnesium $(\mathrm{Mg})$, copper $(\mathrm{Cu})$, iron $(\mathrm{Fe})$ and manganese $(\mathrm{Mn})$ were assessed by an atomic absorption spectrophotometer according to Zhanget al. (2014).
Statistical analysis

Data (means $\pm \mathrm{SD}, n=5$ ) were statistically analyzed by the two-way ANOVA with SAS 8.1 software (SAS Institute Inc., Cary, NC, USA), and the Duncan's multiple range tests were used to determine significant differences between treatments at $P$ $<0.05$.

\section{Results and Discussion}

\section{Root mycorrhizal colonization}

There was no mycorrhizal colonization observed in roots of non-AMF-inoculated white clover plants. The root AMF colonization of the inoculated plants varied from $52.3 \%$ to 76.9\% (Table 1). Compared to WW, DS dramatically decreased root colonization of $F$. mosseae by $19 \%$ and that of $P$. occultum by $32 \%$. This result is coincided with the results of Wu and Xia (2006) in Citrus tangerina. The decrease of root colonization by DS is due to reducing spore germination and plant photosynthetic capacity (Wu et al., 2013). Under WW, $P$. occultum had greater root colonization than $F$. mosseae, indicating stronger potential capacity to apply the field for white clover.

\section{Biomass production}

Compared with WW, DS considerably decreased shoot, root and total biomass in AM and non-AM white clover plants, respectively (Table 1$)$. Inoculation with $F$. mosseae and $P$. occultum significantly increased these biomass productions, irrespective of WW or DS conditions, compared with nonAMF inoculation (Table 1). This result accorded with the finding of Zhao et al. (2015). The positive effect of AMF on growth performance of the host plant is likely due to the improvement in $\mathrm{P}$ nutrition and water by extraradical hyphae (Habibzadeh et al., 2013; Wu et al., 2013). In addition, $P$. occultum-inoculation performed relatively greater effects on stimulating biomass production than $F$. mosseae-inoculation, especially under WW, which is associated with the compatibility between AMF and host plants.

\section{Changes in root flavonoid}

Drought stress treatment significantly decreased root flavonoid levels in non-AMF plant while notably increased root flavonoid concentrations in $F$. mosseae- and $P$. occultumcolonized plants, compared with WW treatment (Fig. 1). Inoculation with $F$. mosseae and $P$. occultum did not change root flavonoid levels under WW but significantly increased root flavonoid concentrations by $77 \%$ and $108 \%$ under DS condition, respectively (Fig. 1).

This result was similar to the view of Abbaspour et al. (2012) who observed the increase in leaf flavonoid content in pistachio (Pistachia vera L.) under both WW and DS after inoculation with $G$. etunicatum. Flavonoids are one of major secondary metabolites in most vascular plants, which can eliminate reactive oxygen species to protect plants from oxidative damage (Wu et al., 2014). As a result, greater root flavonoid levels in AM white clover will confer stronger ability in the host plant to alleviate oxidative stress. However, in rose geranium, F. mosseae and Glomus intraradices both induced the reduction of flavonoid under DS (Amiri et al., 2015). The results imply that AMF-modulated flavonoid changes are 
222

Table 1. Plant growth traits and biomass of AMF or non-AMF white clover (Trifolium repens L.) seedlings grown under well-watered (WW) and drought stress (DS) conditions

\begin{tabular}{|c|c|c|c|c|c|}
\hline \multirow{2}{*}{ Water regime } & \multirow{2}{*}{$\begin{array}{c}\text { Mycorrhizal } \\
\text { status }\end{array}$} & \multirow{2}{*}{$\begin{array}{c}\text { Root AMF } \\
\text { colonization (\%) }\end{array}$} & \multicolumn{3}{|c|}{ Biomass (g FW/plant) } \\
\hline & & & Root & Shoot & Total \\
\hline \multirow{3}{*}{ WW } & F.mosseae & $66.7 \pm 5.2 b$ & $1.09 \pm 0.07 \mathrm{~b}$ & $3.96 \pm 0.24 b$ & $5.05 \pm 0.27 b$ \\
\hline & P. occultum & $76.9 \pm 8.8 \mathrm{a}$ & $1.27 \pm 0.12 \mathrm{a}$ & $4.27 \pm 0.20 \mathrm{a}$ & $5.54 \pm 0.26 \mathrm{a}$ \\
\hline & Non-AMF & $0 \mathrm{e}$ & $0.97 \pm 0.08 \mathrm{~cd}$ & $3.45 \pm 0.24 c$ & $4.42 \pm 0.25 c$ \\
\hline \multirow{3}{*}{ DS } & F.mosseae & $54.2 \pm 3.4 \mathrm{c}$ & $0.95 \pm 0.03 \mathrm{~d}$ & $2.57 \pm 0.10 \mathrm{~d}$ & $3.52 \pm 0.10 \mathrm{~d}$ \\
\hline & P. occultum & $52.3 \pm 3.7 c$ & $1.06 \pm 0.07 b c$ & $2.68 \pm 0.33 \mathrm{~d}$ & $3.74 \pm 0.34 \mathrm{~d}$ \\
\hline & Non-AMF & $0 \mathrm{e}$ & $0.85 \pm 0.02 \mathrm{e}$ & $2.11 \pm 0.15 \mathrm{e}$ & $2.96 \pm 0.13 \mathrm{e}$ \\
\hline \multicolumn{6}{|l|}{ Significance } \\
\hline DS & & $* *$ & ** & $* *$ & ** \\
\hline $\mathrm{AMF}$ & & $* *$ & $* *$ & ** & $* *$ \\
\hline $\mathrm{DS} \times \mathrm{AMF}$ & & $* *$ & NS & NS & NS \\
\hline
\end{tabular}

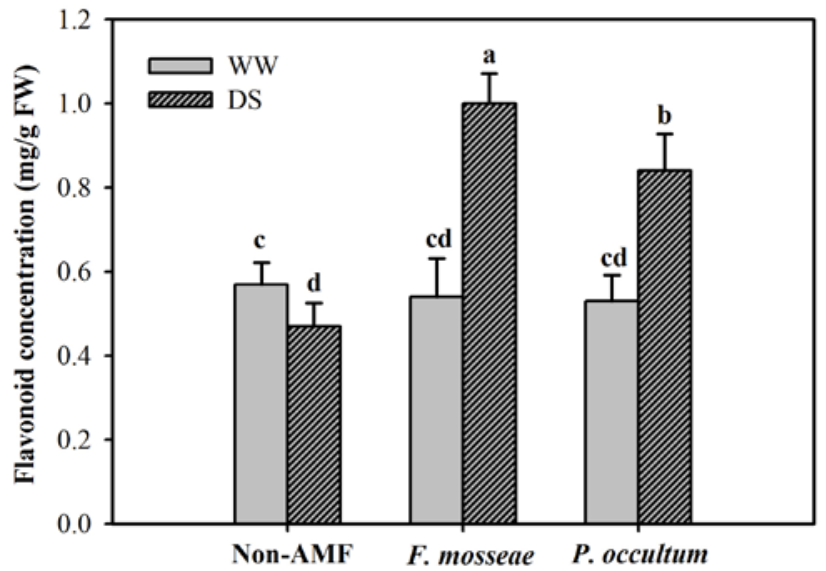

Fig. 1. Effects of Funneliformis mosseae and Paraglomus occultum on root flavonoid concentrations of white clover (Trifolium repens) seedlings under well-watered (WW) and drought stress (DS) conditions. Data (means $\pm \mathrm{SD}, n=5)$ are significantly different $(P<0.05)$ if followed by different letters above the bars

dependent on AMF species, host plant species, and droughtstressed strength.

\section{Changes in root soluble protein}

Root soluble protein concentrations were significantly decreased by DS over WW, irrespective of AM and non-AM plants (Fig. 2).

Under WW conditions, $F$. mosseae and $P$. occultum markedly elevated root soluble protein concentrations by $75 \%$ and $104 \%$, respectively, over non-AMF treatment (Fig. 2). Under DS conditions, $F$. mosseae and $P$. occultum-colonized plants recorded $27 \%$ and $28 \%$ significantly higher root soluble protein concentrations, compared with non-AMF-colonized plants. It seems that AMF inoculation was involved in the increase in root soluble protein concentrations under DS. Similar finding was reported by Huang et al. (2014) in trifoliate orange plants. The increase of soluble protein under mycorrhization might be involved in the decrease in RNA disintegration and in stimulating new protein production under DS.

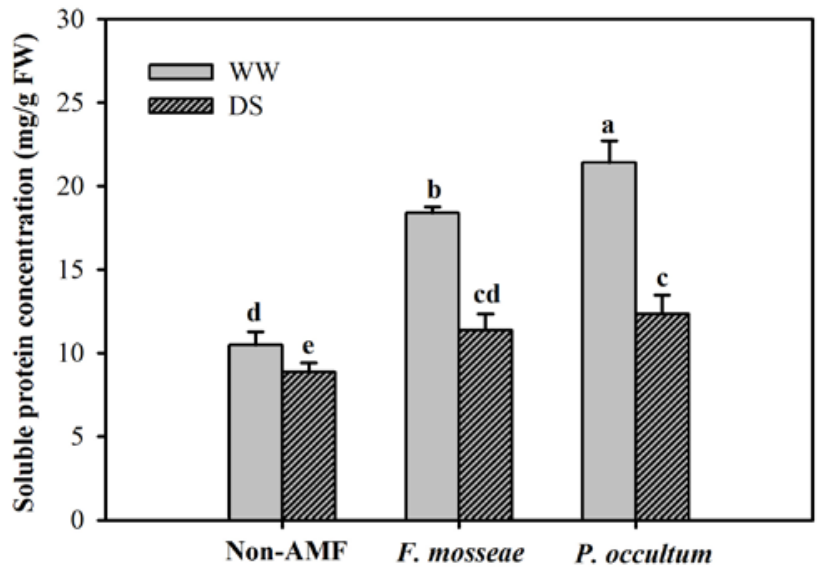

Fig. 2. Effects of Funneliformis mosseae and Paraglomus occultum on root soluble protein concentrations of white clover (Trifolium repens) seedlings under well-watered (WW) and drought stress (DS) conditions. Data (means \pm SD, $n=5$ ) are significantly different $(P<0.05)$ if followed by different letters above the bars

\section{Changes in root proline}

Proline, one of crucial osmoprotectants under adversity conditions, plays a key role in scavenging reactive oxygen species and facilitating water uptake (Ruiz-Sánchez et al., 2010). DS treatment resulted in an increased change in root proline concentrations, regardless of AM and non-AM plants (Fig. 3). The present results further showed that compared with nonAMF treatment, $F$. mosseae and $P$. occultum dramatically increased root proline concentrations by $55 \%$ and $101 \%$ under WW and by $153 \%$ and $118 \%$ under DS, respectively (Fig. 3), which also conformed the early finding of Wu et al. (2013). It seems that the AMF plants possess a better capacity of osmotic adjustment relative to non-AMF plants under DS. Furthermore, the increment in proline could be due to the induction of proline biosynthesis enzymes (P5CS) and to the reduction of degradation enzymes (ProDH) (Tuo et al. 2015). In contrast to drought-induced proline accumulation in AMF plants, studies in the past had observed a remarkable reduction of proline in the pistachio and trifoliate orange plants subjected to DS (Abbaspour et al., 2012; Zou et al., 2013). These results 
Table 2. Root nutrient concentrations in AMF or non-AMF white clover (Trifolium repens L.) seedlings grown under well-watered (WW) and drought stress (DS) conditions

\begin{tabular}{|c|c|c|c|c|c|c|c|c|c|}
\hline $\begin{array}{l}\text { Water } \\
\text { regime }\end{array}$ & $\begin{array}{c}\text { Mycorrhizal } \\
\text { status }\end{array}$ & $\begin{array}{c}\mathrm{N} \\
(\mathrm{mg} \mathrm{DW} / \mathrm{g})\end{array}$ & $\begin{array}{c}\mathrm{P} \\
(\mathrm{mg} \mathrm{DW} / \mathrm{g})\end{array}$ & $\begin{array}{c}\mathrm{K} \\
(\mathrm{mg} \mathrm{DW} / \mathrm{g})\end{array}$ & $\begin{array}{c}\mathrm{Ca} \\
(\mathrm{mg} \mathrm{DW} / \mathrm{g})\end{array}$ & $\begin{array}{c}\mathrm{Mg} \\
(\mathrm{mg} \mathrm{DW} / \mathrm{g})\end{array}$ & $\begin{array}{c}\mathrm{Fe} \\
(\mathrm{mg} \mathrm{DW} / \mathrm{g})\end{array}$ & $\begin{array}{c}\mathrm{Cu} \\
(\mu \mathrm{g} \mathrm{DW} / \mathrm{g})\end{array}$ & $\begin{array}{c}\mathrm{Mn} \\
(\mu \mathrm{g} \mathrm{DW} / \mathrm{g})\end{array}$ \\
\hline \multirow{3}{*}{ WW } & F.mosseae & $17.40 \pm 0.7 \mathrm{c}$ & $3.74 \pm 0.07 a$ & $10.5 \pm 0.19 a$ & $5.11 \pm 0.10 \mathrm{a}$ & $3.13 \pm 0.11 \mathrm{c}$ & $1.72 \pm 0.10 \mathrm{a}$ & $29.90 \pm 1.9 \mathrm{a}$ & $47.69 \pm 1.7 b$ \\
\hline & P. occultum & $18.59 \pm 0.6 b$ & $3.16 \pm 0.10 b$ & $9.54 \pm 0.14 \mathrm{c}$ & $5.32 \pm 0.25 \mathrm{a}$ & $3.84 \pm 0.16 \mathrm{a}$ & $1.77 \pm 0.12 \mathrm{a}$ & $28.52 \pm 2.5 \mathrm{a}$ & $56.68 \pm 3.0 \mathrm{a}$ \\
\hline & Non-AMF & $14.11 \pm 0.5 \mathrm{e}$ & $2.22 \pm 0.02 c$ & $8.81 \pm 0.30 \mathrm{~d}$ & $4.44 \pm 0.04 c$ & $3.46 \pm 0.0 \mathrm{~b}$ & $1.36 \pm 0.04 c$ & $16.65 \pm 0.9 c$ & $41.75 \pm 1.6 c$ \\
\hline \multirow{3}{*}{ DS } & F.mosseae & $18.54 \pm 0.6 b$ & $3.24 \pm 0.10 \mathrm{~b}$ & $10.91 \pm 0.2 \mathrm{a}$ & $4.74 \pm 0.12 b$ & $2.75 \pm 0.1 \mathrm{~d}$ & $1.48 \pm 0.07 \mathrm{~b}$ & $20.52 \pm 1.6 b$ & $42.45 \pm 1.9 c$ \\
\hline & P. occultum & $19.68 \pm 0.2 \mathrm{a}$ & $3.25 \pm 0.11 b$ & $10.17 \pm 0.1 b$ & $4.55 \pm 0.31 \mathrm{c}$ & $2.34 \pm 0.06 \mathrm{e}$ & $1.34 \pm 0.07 \mathrm{c}$ & $19.80 \pm 0.7 \mathrm{~b}$ & $43.48 \pm 1.1 \mathrm{c}$ \\
\hline & Non-AMF & $16.09 \pm 0.3 \mathrm{~d}$ & $2.34 \pm 0.12 c$ & $8.95 \pm 0.54 \mathrm{~d}$ & $4.67 \pm 0.13 c$ & $3.39 \pm 0.2 \mathrm{~b}$ & $1.37 \pm 0.03 c$ & $15.02 \pm 0.8 \mathrm{c}$ & $44.32 \pm 1.4 \mathrm{c}$ \\
\hline \multicolumn{10}{|c|}{ Significance } \\
\hline DS & & ** & ** & ** & ** & $* *$ & ** & $* *$ & $* *$ \\
\hline AMF & & ** & ** & ${ }^{* *}$ & ** & ** & ** & ** & ** \\
\hline $\mathrm{DS} \times \mathrm{AMF}$ & & NS & $* *$ & NS & $* *$ & ** & ** & ** & ** \\
\hline
\end{tabular}

Note: Means \pm SD $(n=5)$ with different letters are significantly different $(P<0.05)$. NS-not significant. ${ }^{* *} P<0.01$.

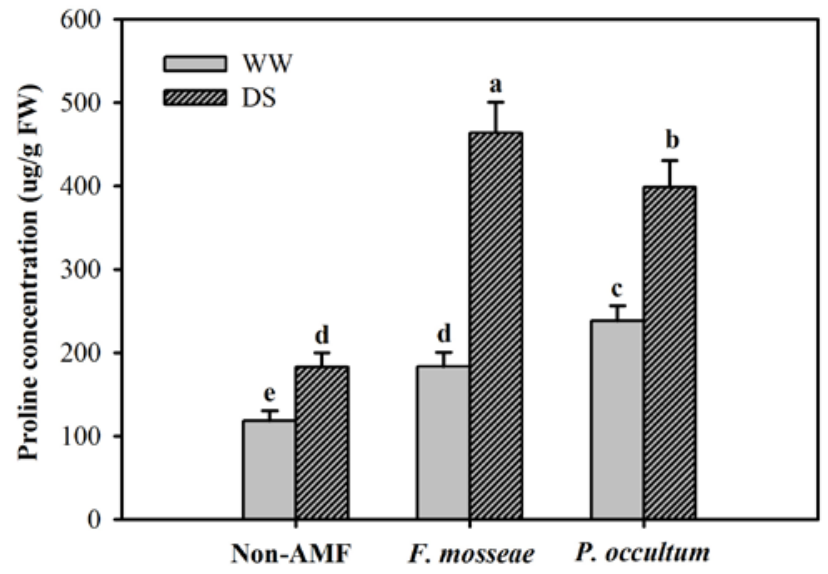

Fig. 3. Effects of Funneliformis mosseae and Paraglomus occultum on root proline concentrations of white clover (Trifolium repens) seedlings under well-watered (WW) and drought stress (DS) conditions. Data (means \pm SD, $n=5$ ) are significantly different $(P<0.05)$ if followed by different letters above the bars

indicate two strategies of AMF responses to DS: drought resistance (higher proline accumulation) and drought avoidance (lower proline accumulation) (Wu et al., 2013).

\section{Changes in root nutrients}

Compared with non-AMF treatment, inoculation with $F$. mosseae and $P$. occultum significantly increased root $\mathrm{N}, \mathrm{P}, \mathrm{K}$, $\mathrm{Ca}, \mathrm{Fe}, \mathrm{Cu}$ and $\mathrm{Mn}$ concentrations under WW (Table 2). Root $\mathrm{Mg}$ concentration was significantly increased by $P$. occultum while decreased by $F$. mosseae under WW. Under DS, inoculation with $F$. mosseae and $P$. occultum notably increased $\mathrm{N}, \mathrm{P}, \mathrm{K}$, and $\mathrm{Cu}$ levels in roots, irrespective of AMF species. In addition, AMF inoculation did not markedly alter root $\mathrm{Ca}$ and $\mathrm{Mn}$ concentration, but decreased heavily root $\mathrm{Mg}$ concentration under DS. F. mosseae significantly increased root Fe levels but $P$. occultum did not alter root Fe levels under DS. It concludes that inoculation with AMF could effectively promote nutrient absorption under DS, especially N, P, K, and $\mathrm{Cu}$. This result supported earlier studies (Li et al., 2014). Mycorrhizal fungi provided greater surface areas of mineral nutrient absorption for host plants by extended extraradical hyphae into soils (Schnepf et al., 2011). Ruiz-Sánchez et al.
(2010) noted that the improvement of $\mathrm{N}$ and $\mathrm{P}$ increased stomata conductance, leaf water potential, and photosynthetic efficiency, thus, enhancing drought tolerance of plants. In addition, both $F$. mosseae and $P$. occultum benefited to the uptake of $\mathrm{Ca}, \mathrm{Mg}, \mathrm{Fe}$, and $\mathrm{Mn}$ under WW, whereas such effects were gradually lost under DS. This implies that the enhancement of part mineral nutrients by mycorrhization relies upon the status of both soil water and root mycorrhizal colonization. This result is in agreement with earlier studies in peach (Wu et al., 2011).

\section{Conclusions}

Mycorrhizal inoculation with $F$. mosseae and $P$. occultum considerably enhanced drought tolerance of white clover plants via the improvement in proline, soluble protein, flavonoid and nutrient uptake. It is worthy to note that inoculation with $F$. mosseae and $P$. occultum have the capacity to enhance drought tolerance of white clover, and thereby are uses in virescence and grassy lawn.

\section{Acknowledgements}

This study was supported by the Plan in Scientific and Technological Innovation Team of Outstanding Young, Hubei Provincial Department of Education (T201604).

\section{References}

Abbaspour H, Saeidi-Sar S, Afshari H, Abdel-Wahhab MA (2012). Tolerance of mycorrhiza infected pistachio (Pistacia vera $\mathrm{L}$.) seedling to drought stress under glasshouse conditions. Journal of Plant Physiology 169:704709.

Amiri R, Nikbakht A, Etemadi A (2015). Alleviation of drought stress on rose geranium [Pelargonium graveolens (L.) Herit.] in terms of antioxidant activity and secondary metabolites by mycorrhizal inoculation. Scientia Horticulturae 197:373-380.

Bradford MM (1976). A rapid and sensitive method for the quantitation of microgram quantities of protein utilizing the principle of protein-dye binding. Analytical Biochemistry 72:248-254.

Bates LS, Waldren RP, Teare ID (1973). Rapid determination of free proline for water stress studies. Plant and Soil 39:205-207. 
224

Chapman HD, Pratt PF (1962). Methods of analysis for soils, plants and water.Soil Science 93:68-70.

Chen SY, Wang Y, LiJK, Gu MR, Shu HR (2001). Studies on the change of flavone contents and its distribution in Ginkgo biloba leaves. Acta Horticulturae Sinica 28:353-355.

Habibzadeh Y, Pirzad A, Zardashti MR, Jalilian J, Eini O (2013). Effects of arbuscular mycorrhizal fungi on seed and protein yield under waterdeficit stressin mungbean. AgronomyJournal 105:79-84.

Huang YM, Srivastava AK, Zou YN, Ni QD, Han Y, Wu QS (2014). Mycorrhizal-induced calmodulin mediated changes in antioxidant enzymes and growth response of drought-stressed trifoliate orange. Frontiers in Microbiology 5:1-7.

Kapoor R, Giri B, Mukerij KG (2004). Improved growth and essential oil yield and quality in Foeniculum vulgare mill on mycorrhizal inoculation supplemented with P-fertilizer. Bioresource Technology 93:307-311.

Lazcano C, Barrios-Masias FH, Jackson LE (2014). Arbuscular mycorrhizal effects on plant water relations and soil greenhouse gas emissions under changing moisture regimes. Soil Biology and Biochemistry 74:184 192.

Li T, Lin G, Zhang X, Chen YL, Zhang SB, Chen BD (2014). Relative importance of an arbuscular mycorrhizal fungus (Rhizophagus intraradices) and root hairs in plant drought tolerance. Mycorrhiza 24:595-602.

Li T, Liu RJ, He XH, Wang BS (2012). Enhancement of superoxide dismutase and catalase activities and salt tolerance of euhalophyte Suaeda salsa L. by mycorrhizal fungus Glomus mosseae. Pedosphere22:217-224.

Li Z, Peng Y (2012). Photosynthetic characteristics and variation of osmoregulatory solutes in two white clover (Trifolium repens L.) genotypes in response to drought and post-drought recovery. Australian Journal ofCropScience 6:1696-1702.

Phillips JM, Hayman DS (1970). Improved procedures for clearing roots and staining parasitic and vesicular-arbuscular mycorrhizal fungi for rapid assessment of infection. Transactions of the British Mycological Society 55:158-161.

Ruiz-Sánchez M, Aroca R, Muñoz Y, Polón R, Ruiz-Lozano JM (2010). The arbuscular mycorrhizal symbiosis enhances the photosynthetic efficiency and the antioxidative response of rice plants subjected to drought stress. Journal of Plant Physiology 167:862-869.

Saraswathi SG, Paliwal K (2011). Drought induced changes in growth, leat gas exchange and biomass production in Albizia lebbeck and Cassia siamea seedlings. Journal of Environmental Biology 32:173-178.

Schnepf A, Jones D, Roose T (2011). Modelling nutrient uptake by individual hyphae of arbuscular mycorrhizal fung: temporal and spatial scales for an experimental design. Bulletin of Mathematical Biology 73:2175-2200.
Sivasankar S, Oaks A (1995). Regulation of nitrate reductase during early seedling growth (A role for asparagine and glutamine). Plant Physiology 107:1225-1231.

Smith SE, Facelli E, Pope S, Andrew Smith F (2010). Plant performance in stressful environments: Interpreting new and established knowledge of the roles of arbuscular mycorrhizas. Plant and Soil 326:3-20.

Tuo XQ, LiS, Wu QS, Zou YN (2015). Alleviation of waterlogged stress in peach seedlings inoculated with Funneliformis mosseae: Changes in chlorophyll and proline metabolism. Scientia Horticulturae 197:130134.

Wu QS, Li GH, Zou YN (2011). Roles of arbuscular mycorrhizal fungi on growth and nutrient acquisition of peach (Prunus persica L. Batsch) seedlings.Journal of Animal and Plant Sciences 21(4):746-750.

Wu QS, Srivastava AK, Zou YN (2013). AMF-induced tolerance to drought stress in citrus: A review. Scientia Horticulturae 164:77-87.

Wu QS, Xia RX (2006). Arbuscular mycorrhizal fungi influence growth, osmotic adjustment and photosynthesis of citrus under well-watered and water stress conditions. Journal of Plant Physiology 163:417-425.

Wu QS, Zou YN, Abd-Allah EF (2014). Mycorrhizal association and ROS in plants. In: Ahmad, P.(Ed.), Oxidative Damage to Plants Antioxidant. Academic Press. pp 453-475.

Wu QS, Srivastava AK, Cao MQ (2016a). Systematicness of glomalin in roots and mycorrhizosphere of a split-root trifoliate orange. Plant Soil and Environment 62: 508-514.

Wu QS, Wang S, Srivastava AK (2016b). Mycorrhizal hyphal disruption induces changes in plant growth, glomalin-related soil protein and soil aggregation of trifoliate orange in a core system. Soil and Tillage Research 160:82-91.

Zhang BB, Chang SX, Anyia AO (2016). Mycorrhizal inoculation and nitrogen fertilization affect the physiology and growth of spring wheat under two contrasting water regimes. Plant and Soil 398:47-57.

Zhang Y, Yao Q, LiJ, Hu YL (2014). Growth response and nutrient uptake of Eriobotrya japonica plants inoculated with three isolates of arbuscular mycorrhizal fungi under water stress condition. Journal of Plant Nutrition 37:690-703.

Zhao RX, Guo W, Bi N, Guo JY, Wang LX, Zhao J, Zhang J (2015). Arbuscular mycorrhizal fungi affect the growth, nutrient uptake and water status of maize (Zea mays L.) grown in two types of coal mine spoils under drought stress. Applied Soil Ecology 88:41-49.

Zou YN, Wu QS, Huang YM, Ni QD, He XH (2013). Mycorrhizalmediated lower proline accumulation in Poncirus trifoliata under water deficit derives from the integration of inhibition of proline synthesis with increase of proline degradation. PLOS ONE 8:e80568. 